\title{
BİR WEB 2.0 UYGUALAMASI OLARAK BLOGLAR: BLOGLARIN DINAMIKLERİ ve BLOG ALEMİ
}

\author{
Şakir ÖZÜDOĞRU \\ Anadolu Üniversitesi, Mimarlık ve Tasarım Fakültesi, Moda Tasarımı Bölümü \\ sakiro@anadolu.edu.tr
}

\begin{abstract}
ÖZET
Bloglar, kișisel düșüncelerin ve ağ bağlantılarının ağ üstünde yayınlandığı alanlar olarak tanımlanmaktadır. Bloglar yeni bir gazeteciliğin doğuşu olarak görüldüğü gibi demokrasiye şekil vermenin yeni bir yolu ve kâr amacı güden şirketler için güçlü birer pazarlama aracı olarak ele alınmıştır. Bunların yanında kişisel duygu ve düşüncelerini bir günlük biçimde ağ üstüne paylaşan kişilerin sayısı azımsanacak ölçüde değildir. Bu çalışmanın amacı, blog kullanımı ile ilgili son dönem çalışmaları değerlendirmektir. Çalışmanın birinci bölümünde blog kullanımı ile ilgili istatistiki veriler sunulmuştur. İkinci bölümde kişisel ve kurumsal blog kullanıcılarının blogları kullanma motivasyonları ele alınmıştır. Üçüncü bölümde blogların kullanım alanlarına değinilmiş ve bu alanlar gazetecilik, politika, eğitim ve pazarlama başlıkları altında değerlendirilmiştir. Sonuç bölümünde sunulan bulgular 1şı̆̆ında blogların olumlu ve olumsuz yanları tartışılmış, gelecek çalışmalar için çeşitli önerilerde bulunulmuştur.
\end{abstract}

Anahtar Sözcükler: Web 2.0, Blog, Weblog, Blogosphere

\section{BLOGS AS A WEB 2.0 APPLICATION: DYNAMICS OF BLOGS AND BLOGOSPHERE}

\begin{abstract}
Blogs are defined as spheres in where personal ideas and networks presented on the Web. Blogs, also, believed as the birth of a newfangled kind of a journalism as well as a means of shaping democracy. Plus, blogs are significant marketing tools for profit motive institutions. Besides this, the amount of people who share personal feelings and ideas on the Web as a diary can not be underestimated. This study aims to consider recent studies on blogs. In the first part of the study a wide range of statistical data about using of blogs is presented. In the second part, motivations of personal and institutional blog users are addressed. In the third part, the question of in which fields blogs are used tried to be answered and these fields are considered under four themes as "journalism", "politics", "education", and "marketing". In conclusion, in the light of the findings presented positive and negative sides of blogs are discussed and suggestions are made for further studies.
\end{abstract}

Keywords: Web 2.0, Blog, Weblog, Blogosphere

\section{GíRiş}

İletişim teknolojilerindeki gelişmeler mikro-elektronik, bilgisayar ve telekomünikasyon alanlarında ortaya çıkan gelişmelerin bir sonucu olarak 1970'lerde yaygınlık kazanmış, 1980'ler ve 1990'lar arasında ise yüksek bir ivme ile artış göstermiştir (Castells, 2008). 1980'li yıllarda kişisel bilgisayarlar ticarileşmiş, 1990'larda internet yaygınlık kazanmış ve 2000'li yıllarda ise bilgisayar aracılığıyla iletişim gündelik yaşamın bir parçası olmuştur (Köseoğlu, 2012). Bu dönemde bilgisayarlar küçülmüş, ucuzlamış ve taşınabilir hâle gelmiştir. Donanım alanındaki gelişmelere paralel olarak telekomünikasyon teknolojileri de gelişmiştir. Yaygın olarak kısaltması "WWW" olarak bilinen "World Wide Web" protokolü İsviçre'de CERN'de geliştirilmiş ve 1994 yılında kullanıma açılmıştır. Bu teknolojinin ilk aşaması Web 1.0 olarak adlandırılmıştır. Web 1.0 teknolojisi ile birçok internet sitesi birbirine bağlanmış, kullanıcıların kişisel ya da kurumsal sayfaları üstünde çeşitli bağlantıları paylaşmaları ile ağ içinde dolaşım oranı artmıştır (Kinsela vd., 2010). Web 1.0 kullanıcılara kısıtlı olanaklar sunmakta, içerik durağan bir şekilde ağda bulunmakta, sunucu ile etkileşim içine girmeye izin vermemektedir. Bu teknolojide çok küçük bir kısım kullanıcı içerik 
üreticisi iken, kullanıcıların büyük bir kısmı sunulan içeriği sadece görebilmektedir (Krishnamurthy ve Cormode, 2008). 2000'li yıllarda amac1 sadece bilgi sunmak olan ortamlardan öteye geçen bilgi paylaşımına ve içerik oluşturmaya izin veren ortamlar geliștirilmiştir. Bu ortamlara verilen isim Web 2.0 olmuştur. Terim ilk kez, darcy DiNucci (1999)'nin "Fragmented Future" isimli makalesinde kullanılmış ve Tim O'Reilly (2005) tarafından bir konferans sırasında akademik dünyaya tanıtılmıştır. Web 2.0, herkesin içerik yaratıcısı olabilmesine, müdahale edilebilen siteler yaratılmasına, yazılı, görüntülü ve sesli materyaller gibi çeşitli materyallerin paylaşılmasına olanak tanımaktadır. Aynı zamanda etiketleme, yorum bırakma ve grup içi ya da grup dişı bağlantılar oluşturabilme özellikleri ile içerik yaratıcısı ya da yaratıcılarının ve bu içeriği takip edenlerin etkileşim içine girmesine, dolayısıyla çevrimiçi topluluklar oluşturmasını imkanlı kılmaktadır (Krisnamurthy ve Cormode, 2008).

İçeriğin kullanıcılar tarafından girildiği, kullanıcıların kendilerine bir profil oluşturmalarına ve diğer kullanıcıların girdiği içeriklere yorum yapabilmelerine izin veren sosyal medya siteleri Web 2.0 tabanlı internet sitelerine örnektir. Sosyal medya siteleri karakteristik özellikleri göz önünde bulundurularak altı kategori altında toplanabilir. $\mathrm{Bu}$ kategoriler şunlardır: kullanıcıların görüntülü ve sesli içerikleri paylaştıkları YouTube, Daliymotion gibi içerik paylaşım siteleri, kullanıcıların bilgi paylaşımında bulundukları ve ortak içerikler ürettikleri Wikipedia, Wikiscience gibi ortak ansiklopediler, kullanıcılara profil oluşturma, her an çevrimiçi etkileşimde bulunma, duygu, düşünce ve her türlü materyal paylaşmaya izin veren Facebook, MySpace gibi sosyal ă̆ siteleri, kullanıcıların içeriğini kendilerini oluşturdukları ve bir çeşit günlük gibi işlev gören blog siteleri, kullanıcıların ortak bir dünya üzerinde belirli amaçları başarmak için bir araya geldiği World of Warcraft, Diablo 3 gibi çevrimiçi oyun siteleri ve kullanıcıların kendilerine bir avatar yaratarak bir simülasyon içinde avatarları aracılığıyla sosyal etkileşimde bulundukları Second Life, Sims Online gibi sanal dünyalar (Kaplan ve Haenlein, 2010).

$\mathrm{Bu}$ çalışmanın konusu olan blog siteleri ortaya çıktıkları günden beri pazarlama ve tanıtım etkinliklerinin etkin birer mecrası hâline gelmiştir. Yanı sıra blog siteleri kullanıcı dostu ara yüzleri, ücretsiz hizmet vermeleri ve kullanıcıların etkileşimine izin vermeleri gibi nedenler sayesinde kişisel internet kullanıcıları için gündelik deneyimlerini, fikirlerini, duygularını paylaştıkları popüler mecralar olagelmişlerdir. Blog siteleri, güçlü bir iki yönlü iletişim aracıdırlar; kullanıcılar kolayca içerik girebildikleri gibi bu içeriklere yorum yazılabilmekte, bağlantılar verilebilmektedir. Bu siteler süreli bir yayın gibi kronolojik olarak girilen içerikleri arşivledikleri için takip edilmeleri kolaydır. Blog sitelerinin birçoğu birbiri ile bağlantılıdır, blog yazarları ilişkili oldukları diğer blog sitelerini kendi bloglarında listeleyebilmektedirler. $\mathrm{Bu}$ nedenle blog sitelerinin içinde yer aldığ 1 alan, "blog alemi" ya da "blog küre" olarak Türkçeye çevrilebilecek "blogosfer” olarak adlandırılmaktadır (Murugesan, 2007).

$\mathrm{Bu}$ çalışma bir derleme çalışması olup, çalışmada bloglar hakkındaki güncel araştırmalar taranmıştır. İnternet üstünde yapılan araştırmada Türkçe herhangi bir kaynakta blogların etraflıca ele alınmadığı ve bloglar hakkındaki güncel araştırmalara yapılan atıfların azlığı dikkat çekmektedir. Bloglar hakkındaki güncel araştırmalara bakıldığında, bu çalışmaların blogları dört ana başlık altında incelediği gözlenmektedir. Bu başlıklar, gazetecilik, politika, eğitim ve pazarlamadır. Bu çalışmada da sözü edilen başlıklar altında blogların özellikleri ve işlevleri tartışılmaktadır. Öncelikle bloglar hakkındaki istatistiki veriler paylaşılmakta, ardından blog kullanıcılarının motivasyonları ele alınmakta ve bloglar bu başlıklar altında incelenmektedir. Son olarak ileriki çalışmalara yönelik öneriler getirilmiştir. 


\section{BLOG ALEMİ VE BLOGLARLA İLGİİ BAZI İSTATISTIKKSEL VERİLER}

Blog, "weblog" kavramının kısaltılmış halidir. Blog sözcüğünün Türkçe karş1lığ1 olarak "web günlüğü”, “internet güncesi”, "ağ günlüğü”, "çevrimiçi günlük” gibi kavramlar önerilmiştir (Çelebi, 2009: 57). Weblog ya da "blog”, Webhosting Glossary' de kişilerin düşüncelerini ve ağ bağlantılarını periyodik olarak paylaştıkları çevrimiçi yayınlar olarak tanımlanmaktadır. Blogların bir insanın hayatında ya da ağda ne tip şeyler olup bittiği hakkında bilgi veren bir tür melez yayın olduğu söylenebilir (Aktaran: Brown, 2005). Blogların ortaya çıkışı kişisel günlüklerin çevrimiçi versiyonları gibi olsa da kısa süre içinde blogların kullanım alanı siyasi kampanyalardan eğitim amaçlı materyallerin paylaşımına, tüketici bloglarından sivil topluma ait kampanyaların duyurulduğu ve tanıtıldığı bloglara kadar yayılmıştır. Axel Bruns ve Joanne Jacobs (2006)'un belirttiğine göre bloglar, ABD başkanlığ 1 seçimlerinde, Londra'daki muhalif hareketlerin örgütlenmesinde ve Irak'tan haber yapan bağımsız gazetecilerin yazdıklarını yaymada önemli bir role sahip olmuşlardır. Tüketim ürünleri hakkındaki fikirlerini çevrimiçi ortamda paylaşan tüketici bloglarının sayısı artmış ve tüketici blogları etkin birer pazarlama mecrası hâline gelmiştir. Şirketler de kendilerine ait blog sayfaları kurarak tüketicileri ile etkileşimli bir iletişim içine girmenin yollarını aramışlar, aramaktadırlar (Wright, 2005).

Pew Center'ın 2004 yılında yaptığı bir araştırmaya göre 32 milyon Amerikalı kendi ilgi alanlarındaki blogları takip etmektedir. İnternet kullanan 120 milyon Amerikalı yetişkinin yüzde 7'si de bir blog sayfası olduğunu belirtmiştir (Bruns ve Jacobs, 2006). Johnson (2012)'a göre 2012 yılının Temmuz ayı itibari ile ABD'de yaklaşık 42 milyon kişi blog kullanmakta, ayda 329 milyon kişi en az bir blogu ziyaret etmekte ve 25 bilyon sayfa görüntülenmektedir. Riley'in verilerine göre ise 2005 yılında, Avustralya'da 450.000 civarında, 2.5 milyon İngiltere'de ve ABD'de 50 milyonun üstünde yayınlanan blog bulunmaktadır. M. Cross (2011)'un sunduğu daha güncel verilere göre, Amerikalı blog yazarları toplam blog yazarlarının yüzde 29.2'sini meydana getirmektedir; bu oran dünyada en çok blog yazarı barındıran ikinci ülke olan İngiltere'nin dört katıdır. Aynı yazarın aktardığ 1 , BlogPulse şirketinin yaptığ bir araştırmada dünyada 22 Mart 2011 tarihinde izi sürülebilen, tanımlı 158.273 .691 blog bulunmaktadır ve aynı gün $72.870 \mathrm{blog}$, blog alemine katılmıştır. Sunulan verilere göre bu çalışmanın kaleme alındığı 2013 yılına kadar geçen sürede blogları takip edenlerin ve blog yazarlarının sayısında büyük ve kritik bir artış göze çapmaktadır.

Blog yazarlarının demografik özelliklerine bakıldığında çeşitlilikler gözlemlenmektedir. Sysomos şirketinin 2010 yılında yayınladığı araştırmaya göre blog yazarlarının yüzde 53.3'ü 21 ve 35 yaş aralığında, yüzde 20.2'si yirmili yaşlarda ya da yirmi yaşından daha küçük, yüzde 19.4'ü 36 ve 50 yaş aralığında ve son olarak yüzde 7.1 'i 51 yaşının üzerindedir. Blog yazarları arasındaki cinsiyet dağımı ise yüzde 50.9'u erkek ve yüzde 49.1'i kadın olmak üzere eşit dağılmış görünmektedir. Blog yazarlarının yaşadıkları yere göre dağılımına bakıldığında, büyük bir çoğunluğun yüzde 29.2 oranıyla ABD'de olduğu görülmektedir. Onu yüzde 6.75 ile İngiltere izlemektedir. Araştırmanın kapsadığı diğer ülkeler ise yüzde 4.9 ile Japonya, yüzde 4.2 ile Brezilya, yüzde 3.9 ile Kanada, yüzde 3.3 ile Almanya, yüzde 3.2 ile İtalya, yüzde 3.1 ile İspanya, yüzde 2.9 ile Fransa ve yüzde 2.3 ile Rusya'dır. Blog kullanıcilarının çoğunluğunu gençlerin oluşturması şaşırtıcı değildir. M. Prensky (2001) sanal iletişim teknolojilerinin içine doğmuş olan gençleri dijital yerliler olarak isimlendirmektedir. Ona göre dijital yerliler bilgiye hızla erişmeyi ve bilgiyi çizgisel olarak değil de oradan oraya atlayarak edinmeyi tercih etmektedirler. Blog uygulamalarının geçmişinin çok uzun olmadığı göz önüne alındığında blog kullanıcılarının çoğunluğunun da bugünün dijital yerlileri olması doğaldır. Blog kullanıcılarının yaşadıkları yere göre dağılımına bakıldığında ise çoğunluğun internetin doğduğu ülke olan ABD’de olduğu görülmektedir. İngiltere hariç diğer ülkelerdeki blog 
kullanıcılarının oranının kritik oranda az olduğu göz önüne alınırsa, bunun internete erişim, ülkelerin internet kısıtlamaları ya da kullanıcıların internetin nasıl kullanılacağını bilmemeleri ve internet teknolojisindeki yenilikleri takip edememelerinden kaynaklanan bir sosyal eşitsizlik mi olduğu yoksa çeşitli nedenlerden dolayı blog uygulamalarını kullanmayı tercih mi etmedikleri ampirik araştırmalara dayanarak cevaplanması gereken sorulardır.

Kullanıcıların blog uygulamalarını kullanım amaçları da değişiklik göstermektedir. Bir grup blog yazarı bloglarını hobi amaçlı kullanmalarına karşın kişisel blogları ekonomik gelir elde etmek için kullanan blog yazarları da mevcuttur. Johnson (2012)'a göre blog kullanıcılarının \%8'ini geçimini sadece sunduğu blogdan sağlamakta, \%9'u günde dört ile altı saat arası blog yazarlığı yaparak geçimini sağlayacak kadar ekonomik gelir elde etmektedir. Sosyal medya araştırmaları yapan bir şirket olan Technorati'nin, 2009 yılında yaptığı incelemeye göre de blog dünyasında yer alan kullanıcıların \%29'u kendilerini blogları aracılığıyla ekonomik gelir sağlayan profesyonel blogcular olarak tanımlamaktadır (MacLean, 2009).

Bütün blog kullanıcılarını ve blogları içine alan topluluğun tümü Türkçeye "blog alemi " ya da "blog küre" olarak çevrilebilecek "blogosphere" olarak adlandırılmaktadır. Blog alemi içinde blog girdileri çapraz bağlantılarla birbirine bağlıdır. Kullanıcının herhangi bir ilgi alanına dair olan bir blogda başlayan yolculuğu onu bu ilgi alanına dair ya da ilgili alanların da içine bulunduğu daha geniş bir bloglar çevrimine taşıyabilir. Bu da blogların tek başına değil ancak belirli bir ilgi alanında birbirine bağlantıları sayesinde ortaya koydukları kolektif gücü göstermektedir (Bruns ve Jacobs, 2006).

Bruns ve Jacobs (2006)'a göre blog uygulamalarının sunduğu ortama ağa erişimi olan herkes katılabilmektedir. Yanı sıra ortama giriş engeli düşük olmakla birlikte bu ortamda yayınlama haklarını denetleyen ya da düzenleyen merkezi bir otorite yoktur; ayrıca blog kullanıcıları çevrimiçi ya da çevrim dışı olarak edindikleri herhangi bir bilgi ya da fikir hakkında kendi görüşlerini özgürce belirtebilmektedirler. $\mathrm{Bu}$ özelliklerinin dışında blogların, blog kullanıcılarına sunduğu farklı özellikler ve kolaylıklar da mevcuttur. Çalışmanın bundan sonraki bölümünde blog kullanıcılarının blogları kullanmadaki motivasyonları ele alınacak ve blog uygulamalarının kullanım alanları örneklenecektir.

\section{BLOG KULLANICILARININ MOTIVASYONLARI}

Blog kullanıcılarının blog uygulamasını kullanma nedenleri farklıklar gösterdiği gibi motivasyonları da farklılıklar göstermektedir. Yine kullanıcıların kişisel kullanıcılar mı yoksa kurum ya da şirketler mi olduğu blog uygulamalarını kullanmadaki neden ve motivasyonları farklılaştırmaktadır. Kişisel kullanıcılar çoğunlukla günlük tutmak/hayatlarını belgelemek, belirli konulardaki düşüncelerini paylaşmak, yazarak kendini belirli bir izleyici kitlesine ifade etmek ve belirli bir ilgi alanı etrafında bir araya gelmek için blogları kullanmaktadırlar (Nardi vd., 2004). Bunlara belirli bir alanda sosyal sermaye sağlamak da eklenebilir. Şirketler ve kurumlar ise blogları geleneksel medyada olduğu gibi kendilerini ve hizmetlerini tanıtmak için kullanmaktadırlar. Genellikle kurumsal blogların amacı kurum içindeki faaliyetleri ve yenilikleri müşterilerine bildirmek olmaktadır (Genç, 2010).

\section{Kişisel Blog Kullanıcılarının Motivasyonları}

B. A. Nardi ve arkadaşlarının (2004) insanların neden blog kullandıkları üstüne yaptıkları araştırmada blog kullanımının öne çıkan nedenlerinden biri insanların yaşamlarını belgeleme isteği olmuştur. Görüşme yapılan kişilerden biri neden blog yazdığı sorusuna blog yazarak "varoluşunun kaydını tuttuğunu" cevabını vermiştir (Nardi vd., 2004: 43). Görüşme 
yapılanlardan bir kısmı ise ailesi, yakın çevresi ve arkadaşları ile iletişimini blog aracılığıyla sağladığını, hayatındaki gelişmelerden onları bu yolla haberdar ettiğini ve böylece herkese birçok e-posta yollamaktan kurtulduğunu belirtmiştir.

Blog kullanıcılarının bir kısmı blog kullanmalarının özgürce yorum yapmalarına olanak tanıdığını söylemektedir. Bloglar geleneksel medyadan farklı olarak yoruma, birbirine bağlantılar vermeye ve paylaşıma açıktır. Bu nedenle fikirlerini bloglar aracılığıyla ya da başka bir blog kullanıcısının girdilerine yorum yaparak ifade etmek kolaylaşmaktadır. Özellikle cinsellik, din, ahlak, politika gibi üstünde uzlaşmaya varılması zor konularda bloglar bir tartışma platformu işlevi görmektedir. CNN, BBC gibi dünyanın büyük ve köklü haber kuruluşları da kendi blog sayfalarında yayınladıkları haberleri kullanıcıların yorumuna açmıştır (Bruns ve Jacobs, 2006).

Bir kısım blog kullanıcısı da blogları bir duygusal boşalma aracı olarak görmektedir. B. A Nardi ve arkadaşları (2004: 44) blogların böyle bir motivasyonla kullanımını "katarsis olarak blog kullanmak" olarak adlandırmıştır. Blog kullanıcıları hayatlarının önemli noktalarındaki ya da onları etkileyen toplumsal ya da kişisel olaylar karşısındaki duygularını blogları aracılığıyla yazınsal bir dil kullanarak aileleri, yakın çevreleri ve arkadaşları ile paylaşmaktadırlar. Benzer olarak bir grup blog kullanıcısı da blog aracığıyla yazarak düşündügünü ifade etmiştir. Bu sayede blog kullanıcıları yazdıklarına şekil veren bir takipçi kitlesi ile buluşmakta ve yazdıklarını bloglarında depolama fırsatı bulmaktadırlar (Nardi vd, 2004). Huang ve arkadaşlarının (2007) yaptığı araştırmada bloglar aracılığıyla duygularını ifade etmek ve yazarak düşünmek kategorileri arasında belirgin sınırlar olmadığı ortaya koyulmuş ve kişisel blog kullanıcılarının bu motivasyonları tek bir başlık altında ele alınmıştır.

Nardi ve arkadaşlarının (2004) araştırmasında blog kullanıcılarının motivasyonları hakkında son olarak ortaya konulan kategori blog aracılığıla bir topluluk oluşturmaktır. Bloglar aracılığıyla çeşitli ilgi alanları hakkındaki bloglar arasında bir bağlantı havuzu yaratılabileceği gibi blog uygulamaları çoklu kullanıcıların da veri girebilmesine izin vermektedir. Politika, edebiyat, eğitim gibi alanlarda gerek yazılı, sesli ve görüntülü verileri paylaşmak gerek belirli konularda bir topluluk içinde fikirlerini ifade etmek gerekse de belirli konularda yorumlarını paylaşmak için insanlar bir araya gelmektedir. Böylece bloglar aracılığıyla sanal bir topluluk oluşturulmakta, insanlar sanal topluluğa aidiyet hissi duymaktadırlar.

Nardi ve arkadaşlarının (2007) araştırmasının bulgularına ek olarak Huang ve arkadaşları (2007) kişisel blog kullanıcılarının motivasyonlarına bilgi arama kategorisini de eklemişlerdir. Hiper bağlantılar sayesinde birçok blogun birbirine bağlanması kolaydır, yanı sıra RSS bildirimleri gibi uygulamalar diğer bloglardaki yeniliklerden blog kullanıcılarını hızlı bir biçimde haberdar etmektedir. Bu nedenle belirli konular hakkında bilgi edinmek isteyen blog kullanıcıları için blog açmak cazip hâle gelmektedir.

Son olarak kişisel blog kullanıcılarının motivasyonlarına kültürel sermaye aracılığıyla sosyal ve ekonomik sermaye edinmek de eklenebilir. Moda blogları hakkında yapılan araştırmalarda moda blogu yazarlarının büyük ve köklü moda firmaları tarafindan blog yazarı olarak tutulduğu, defilelere davet edildiği ya da firmaların bloglarını bu blog kullanıcılarına yaptırdığı ortaya çıkarılmıştır (Marvick, 2011). Fransız düşünür Pierre Bourdieu (1984) kişilerin toplumda kendilerini sunarken ve kendilerini geliştirirken farklı sermayeler kullandıklarını iddia etmektedir. Düşünüre göre ekonomik sermaye kişinin ekonomik durumunu işaret ederken, sosyal sermaye kişilerin içinde bulunduğu sosyal ağları ve ilişkileri 
vurgulamaktadır. Bunun yanında yer alan kültürel sermaye ise kişilerin beğeni ve güzellik algılarının toplum içinde nerede konumlandıklarını belirlemektedir. Farklı sosyoekonomik seviyelerdeki kişiler farklı beğeni, davranış ve tutum örüntülerine sahiptir. Sembolik sermaye bunların hepsinin birleşimi olarak işlev görmektedir. Y. Kawamura (2005)'ya göre modada ürünlerin tüketimi ve kullanımı kişilerin sosyal kimliğini oluşturan sembolik sermayeyi meydana getirmektedir. Herkesin bilgiye ucuz ve kolay bir şekilde ulaşabildiği bilgi çağında sembolik sermayenin başlıca belirleyeni ekonomik sermaye olmaktan çıkmış, kültürel ve sosyal sermaye de ekonomik sermayeye ulaşmanın bir yolu haline gelmiştir. Fashion Toast blogunun kurucusu Rumy Neely Amerikan sokak modası markası RVCA'nın 2010 SonbaharKış koleksiyonun yüzü olmuş; The Satorialist isimli blogun kurucularından Scott Schuman iki sezon boyunca denim firması DKNY'nin modellerini fotoğraflamıştır; aynı blogun kurucularından Garance Dore Glamour Italy dergisi için fotoğraflar çekmek için davet edilmiş ve Vogue Fransa'nın çevrimiçi versiyonunda yazılar yazmaya başlamıştır (Pagett, 2010). Örneklerde de görüldüğü gibi blog yazarlığı kimi zamanlarda da blog yazarlarının kültürel sermayelerini ekonomik ve sosyal sermayeye çevirmelerinin bir yolu da olabilmektedir.

\section{Kurumsal Blog Kullanıcılarının Motivasyonları}

Bloglar genellikle kişisel günlükler olarak ele alınmasına karşın şirketler ve kurumlar da kendi bloglarını oluşturmaktadır. Şirketler için blog uygulamaları bir etkinlik günlüğü, gazete ya da proje yönetim aracı olarak kullanılabilmektedir (Charman, 2006). Kurumsal bloglar "dış şirket blogları" ve "iç şirket blogları" olmak üzere iki kategoriye ayrılmaktadır ve bu kategorilere göre kullanım amaçları ve motivasyonları değişmektedir (Wright, 2005). Dış şirket blogları bir nevi şirketlerin halkla ilişkiler faaliyetlerinin bir parçası olarak işlev görmektedir (Cortini, 2009). İç şirket blogları, sadece şirket içi erişimin olanaklı olduğu ve proje yönetimi, fikir oluşturma ve araştırma, takım ruhu yaratma gibi konularda işlevsel olmaktadır (Akar, 2006).

İç şirket bloglarının motive edicileri üç başlık altında toplanabilir. Kişisel iç şirket blogları, birçok veri ile uğraşmak zorunda olan çalışanlar için verilerin depolanmasında ve verilere ulaşmada kolaylıklar sağlamaktadır. Şirket içi ve dışı ile yapılan görüşmelerden gelen veriler, birçok kaynaktan gelen istatistiksel veriler, şirket hakkındaki haberler ve çalışanın ait olduğu departman hakkındaki veriler kişisel bloglarda kolayca saklanabilmektedir, bu da çalışanları her ay uzun raporlar hazırlamaktan kurtarabilmektedir (Charman, 2006).

İç şirket gruplarının başka bir türü olan grup blogları da kişisel şirket bloglarına benzer olarak verileri depolamakta ve istenildiği zaman bu verilere ulaşmakta kullanılmaktadır; ancak grup bloglarının özelliği şirket içi faaliyetlerin kaydedilmesi ve bu faaliyeti ilgilendiren birimler arası iletişim aracı işlevi görmesidir. Grup blogları sayesinde belirli bir durumda karşılaşılan sorunlar belgelenmekte ve benzer sorunlar için benzer çözüm yolları üretilebildiği gibi farklı birimlerden sorunun çözümü için görüş alınabilmektedir (Charman, 2006).

İç şirket bloglarının üçüncü türü olan şirket blogları da bilgi paylaşımında, bilgi depolamada ve bilgi yönetiminde kolaylıklar sağlamaktadır. Charman (2006)'ın belirttiğine göre piyasada sözü edilen faaliyetleri gerçekleştiren yazılımlar bulunmasına karşın, bu yazılımların kullanımı hem görece zor hem maliyetlidir hem de yazılımı kullanmayı bilmeyen çalışanlar için zaman israfina neden olmaktadır. Bloglar kategori oluşturma, arama yapma, sayfalar arası bağlantılar oluşturma gibi özelliklerinin basit kullanımı sayesinde bilgi yönetiminde tercih edilebilirken; blog yazarı ve okuyucu arasındaki yorumlar ve paylaşımlar aracılığıyla bir etkileşimin ortaya çıkmasına da olanak sağlamaktadırlar. 
Dış şirket blogları ise daha önce değinildiği gibi şirketlerin halkla ilişkiler ve pazarlama faaliyetlerini bir parçası konumundadır; ancak bu hakla ilişkiler ve pazarlama faaliyeti geleneksel olandan farklıdır ve şirketlerle müşterileri arasında etkin bir iletişime izin vermektedir. Şirketler bloglar aracılığıyla müşterilerinden doğrudan geribildirim alabilmekte, ürünlerini ve hizmetlerini bu geribildirimlerin ışığında yeniden düzenleyebilmektedirler (Marken, 2005).

Dış şirket blogları ayrıca geleneksel medyada yayınlanan şirketin ürünlerinin tanıtımına yönelik materyallerden daha hızlı bir biçimde müşterileri bilgilendirmekte, şirkete dair haberlere bu bloglar aracılığıyla çok hızlı bir şekilde ulaşılabilmektedir (Özgüner Kılıç, 2011). Son olarak belirtilmesi gereken dış şirket bloglarının bir ağızdan ağıza pazarlama yöntemi olarak kullanılmasıdır. Pazarlama faaliyetleri içinde ağızdan ağıza pazarlamanın önemi çeşitli çalışmalarda ortaya koyulmuştur (Dahan, 2012; Silverman, 2006; Akar, 2009). Kurumsal bloglar müşteriler arasında bir sanal topluluk hissi yaratarak markaya bağlılığı arttırmakta böylece ağızdan ağıza pazarlama yöntemini etkin bir biçimde kullanabilmektedirler.

\section{BLOGLARIN KULLANIM ALANLARI}

Blogların ucuz maliyeti, kullanım ve ulaşım kolaylığı, özgür erişimli olmaları ve denetimden uzak olmaları gibi özellikleri ortaya çıkmalarından kısa bir süre sonra birçok alana yayılmalarına ön ayak olmuştur. Kişisel hobi bloglarından, kurumsal tanıtım bloglarına, eğitim kurumlarından politik kampanyalara ve sivil toplum kampanyalarına bloglar çok geniş bir yelpazede kullanılmaya başlanmıştır. Sözü edilen kullanım alanlarının hepsini ele almak blogların değişken yapısı düşünüldüğünde çok güçtür; bloglar hakkındaki araştırmalara bakıldığında da bu alanların gazetecilik, eğitim, politika ve pazarlama ana başlıkları altında toplandığı gözlemlenmektedir.

\section{Gazetecilik}

J. Habermas (2012), 17. yüzyıldan itibaren toplumsal yaşamda yapısal dönüşümlerin meydana geldiğini ve bireylerin kendi fikir ve görüşlerini açıkça ortaya koyabildikleri bir platformun ortaya çıktığını iddia etmektedir. Habermas bu platformu "burjuva kamusal alanı" olarak tanımlamakta ve böyle bir platformun ortaya çıkmasında kişilerin bir araya gelip fikirlerini paylaştıkları sosyal alanların varlığı kadar dönemin dergi ve gazetelerinin bu fikirleri yayımlama ve yaymadaki önemine dikkat çekmektedir. S. B. Singer (2006)'in de işaret ettiği gibi demokratik bir toplumda gazeteciliğin görevi yurttaşlara özgür ve özerk bilgi sağlamaktır. Habermas'ın ortaya koyduğu burjuva kamusal alanında zaman içinde politik basın yanlı hâle gelmiş, kapitalist gelişim çizgisinde sermayenin ve sermayedarların yanında yer almaya başlamıştır. Sermayenin hegemonyası kamusal alan üstünde etkili olmuş, farklı fikir ve görüşler sansürlenmeye başlamıştır (Barlow, 2008). Böyle bir ortamda demokrasi fikrinin gelişmesi imkânsızlaşmaktadır. Günümüzde de aynı durum devam etmekte, gazetecilik pratikleri tartışılmakta; devletin ve çeşitli politik uygulamaların medya aracılığıyla yaygınlaştırıldığı ve meşrulaştırıldığı iddia edilmektedir. Amerikalı düşünür N. Chomsky (1993)'e göre ana akım medya iktidar-sermaye-devlet üçgenin de kısılmış ve bu üçgen bir medya denetimi kurmuştur. Demokratik bir rejimde ortaya çıkan bu tip bir medya denetimi insanları gerçek olay ve olgulardan uzaklaştırmış, Chomsky'nin deyişiyle asıl soruları sormaktan alıkoymuştur. Elbette burada sendikal komisyonlar ve İnsan Hakları Gözlemcileri tarafından hazırlanan raporların hasıraltı edildiğini, ana akım medyanın bunlara neredeyse hiç yer vermediğini, deyim yerindeyse bir psikolojik savaş verdiği gerçeğini göz ardı etmemek gerekir. 
Bloglar aracılığıyla gelişen internet haberciliğinin yeni bir gazetecilik türü olup olmadığı ve yeni bir kamusal alan yaratma potansiyeli çeşitli yazarlar tarafından tartışılmaktadır (Singer, 2006; Andrews, 2003; Freidman, 2010; Köse, 2007; Barlow, 2007; Hudson, 2008). Binnaz Saktanber (2007), özellikle Web 2.0'ın ortaya çıkmasından sonra internetin bu gücüne şöyle dikkat çekmiştir:

"Taraflarının devrim veya dijital demokrasi diye öve öve bitiremediği web 2'nin alkışlanmaya değer özelliği, isteyen herkesin, istediği konuda fikrini beyan edebilmesi ve her türlü bilgiyi geleneksel medyanın sansür mekanizmalarından geçirmek zorunda olmadan yayınlayabilmesi."

Saktanber, yukarıdaki alıntında blog gazeteciliğinin de özelliklerine değinmektedir. Blog gazeteciliğinin öne çıkan en önemli özelliklerinden biri, artık herkesin birer haber üreticisi hâline gelebilmesidir. Blog kullanıcıları ilgi duydukları konular hakkındaki gelişmeleri, yakın çevrelerinde meydana gelen ya da tanıklık ettikleri olayları bloglarına taşımakta bizzat haberin kaynağı olmaktadırlar. Böylece ana akım medyanın görmezden geldiği ya da yeterli kamusal ilginin gösterilmeyeceğini düşündüğü olaylar internet ortamında kendi izler kitlesi ile buluşabilmektedir (Andrews, 2003).

Blogların gazeteciliğinin diğer önemli bir özelliği ise haberlerin herkes tarafından yorumlanabiliyor olması ve çoksesliliği teşvik etmesidir. Geleneksel basında haberler editöryel bir sürece tabi olmakta, basın organının tuttuğu tarafa göre şekillenebilmektedir. Okuyucuların ise bu haberler hakkındaki yorumlarına ya hiç yer verilmemekte ya da çok az bir k1smına yer verilebilmekte bu durumda bir kısım okuyucuyu memnun edilirken, yanı sira bir kısım okuyucunun tepkisinin çekilmektedir (Friedman, 2010).

Blog gazeteciliğinin ana akım medyaya göre avantajlarından birinin de görüntü kaydetmeye yarayan aygıtların çoğalması ve yaygınlaşmasıyla hızla olaylara dahil görüntüler elde edebilmeleri ve yaşanan olaya ilişsin görsel kanıtların çoğalması olduğu söylenebilir. 7 Temmuz 2005'de Londra'da gerçekleşen saldırının ardından BBC gibi büyük haber kuruluşları blog kullanıcıları için görsel havuzları oluşturmuşlar ve bu havuzlar kısa sürede olay mahallinden gelen fotoğraflarla dolmaya başlamıştır (Dilmen, 2007). Bu durum, Haziran 2013 tarihinde meydana gelen Taksim Gezi Parkı Protestoları sırasında Türkiye'de de yaşanmış ve hiçbir gazete ya da televizyon kanalı protestolar sırasında yaşananlar hakkında bilgi vermezken birçok blog olayların yaşandığı yerde bulunan kişilerden gelen görüntüleri ilk elden takipçilerine aktarmıştır.

Bloglar geleneksel gazetecilik anlayışına sundukları olanaklar sayesinde yeni kavrayışlar getirirken kimi sorunlar da baş göstermektedir. Bunların başında çoğunlukla haberin kaynağının ortadan kaybolması vardır. Bazı durumlarda da detaylı araştırma yapılmadan haberler hızla ağ aktarılmakta bu da gerçekle çelişkili bir durum ortaya koyabilmektedir (Andrews, 2003). Diğer sorunlu bir durum ise ekonomik olarak güçlü şirketlerin ve siyasi örgütlemelerin yanlı bloglar açarak burada kendi hesabına çalışan blog yazarları aracılığıyla propaganda yapma girişimleridir (Köse, 2007). Böylece blogların sunduğu özgür ortamın Chomsky'nin dikkat çektiği iktidar-devlet-sermaye üçgenince manipüle edilebilir olduğu gözlemlenmektedir. Bütün bunlara karşın blog gazeteciliği, geleneksel gazetecilik anlayışına yeni olanaklar ve kavrayışlar sunmakta, sivil toplum örgütleri için bilgi yayma ve örgütlenme yollar açmakta ve yurttaş gazeteciliğinin önemli bir kanadını oluşturmaktadır.

\section{Politika}

Gazetecilikte olduğu gibi politika alanında da bloglar yeni imkanlar sunmakta ve yeni zorluklar ortaya çıkarmaktadırlar. Özellikle 11 Eylül Saldırılarının ardından Amerikalılar 
yaşadıkları dehşet ve korkuyu bloglar aracılığıyla aktarmış, bloglar Amerikan vatandaşları ve dünya arasında bir köprü işlevi görmüştür. Bu tarihten sonra politik blogların sayısı giderek artmış, Amerika'nın Irak'ı işgali sırasında Irak Savaşı hakkında yayın yapan ve konuya değişik açılardan yaklaşan birçok blog ortaya çıkmıştır. 2004 Amerikan Başkanlığı seçimlerinde ise bloglar çok kritik bir yer edinmiş, L. Adamic ve N. Glance (2005)'a göre seçim kampanyalarının vazgeçilmez bir parçası olmuşlardır. 2006 yılında yapılan bir araştırmaya göre yetişkin Amerikalıların yüzde 7'si politik kampanyalar hakkındaki bilgileri bloglardan edinmektedir. Aynı araştırmaya göre politika aktivistlerinin yüzde 23’ü blogları etkin bir biçimde politik yorumlar yapmak ve politika ile ilgili videolar hazırlanmak gibi politik amaçlarla kullanmışlardır (Perlmutter, 2008). Johnson ve Kaye (2004)'nin araştırması da göstermiştir ki blogları takip edenler bu ortamı bir haber kaynağı olarak diğer çevrimiçi ya da çevrim dışı ortamlardan daha güvenilir bulmaktadırlar.

Blogların politik amaçlarla kullanılmasında öne çıkan önemli yanlarından biri de bir sanal topluluk ve bu sanal topluluğa aidiyet hissi yaratmalarıdır. Politik blogları takip eden kişi sayısı her ne kadar yüksek gibi görünse de politik bloglar kamplara bölünmüştür ve kişiler çoğunlukla kendi ideolojik görüşlerini savunan blogları takip etmekte, burada yorumlar yapmakta ve varlık göstermektedirler. Farrell ve arkadaşlarının (2008) yaptığ 1 araştırmaya göre araştırmanın katılımcılarının yüzde 94'ü karşılarında geniş bir ideolojik perspektif olmasına karşın sadece kendi ideolojik görüsslerinden yana olan blogları takip etmektedirler. M. Bahnisch (2006)'ın iddiası da bu savı doğrulamaktadır. Yazara göre, Amerika Birleşik Devletleri'nde politik bloglar ikiye ayrılmıştır; sağ kanadı Instapundit isimli blog temsil ederken; liberal kanadı Atrios Eschaton ve Daily Kos isimli bloglar temsil etmektedir.

D. D. Perlmutter (2008), politik blogların avantajlarını beş başlık altında toplamaktadır. Yazara göre, politik bloglar aracılığıla insanlar geleneksel medyadan farklı olarak bilgi edinmekte, kurumsal bir eğitimleri olmadan kitle iletişim mesajları üretebilmekte, bazı durumlarda geniş takipçi kitlelerine ulaşabilmekte, diğer insanları bloglarına davet ederek konuk yazar olarak farklı görüşlere yer verebilmekte ve bazı durumlarda güncel kamuoyu üstünde hatta politik kampanyalar ve yönetimlerin politikaları üstünde etkili olabilmektedirler. Bunların yanında politik blogların ana akım medyanın birçok haberi iletmede yetersiz kaldığı ya da baskılandığ 1 ülkelerde yurttaşların sesini duyurmakta ve bu ülkelerdeki politik hareketler hakkında bilgi vermekte etkili olduğu söylenebilir.

Anılan yazarlar dışında politik bloglar hakkında daha birçok araştırma yapılmış ve politik blogların etkisi ortaya koyulmuştur. ABD Başkanlığı Seçimlerinde başkan adayları sosyal medyada etkili kampanyalar düzenlemek için epey çaba sarf etmişlerdir. Bloglar da bu kampanyaların etkin bir aracı olmuştur. Bunun yanında Arap Baharı'nda diğer sosyal medya uygulamalarının yanında bloglar da hem fikirlerin paylaşıldığı hem örgütlenme biçimlerinin konuşulduğu hem de ülkedeki gelişmeler hakkında ülke içine ve dışına haberlerin iletildiği kritik mecralar olagelmiştir (Howard vd., 2011). Irak Savaşı sırasında, savaş blogları önem kazanmış, Iraklı blog yazarları bloglar aracılığıyla dünyaya Irak'ta yaşanan vahşeti duyurmuşlar ve ABD kamuoyu üstünde etki uyandırmışlardır (Curran ve Marshall, 2011). Bunların yanında blog gazeteciliğinin geleneksel gazeteciliğe nazaran daha katılımlı ve özgür bir ortam sunarak çevrimiçi bir kamusal alan yaratma potansiyeli politik bloglar için de geçerli olmakla birlikte (Barlow, 2008), bilginin kaynağının belirsizliği ve manipülasyona açık olması gibi unsurlar yüzünden politik blogları da blog gazeteciliği ile aynı sorunları paylaşır hale getirmektedir. 


\section{Ĕ̆itim}

Blogların diğer bir kullanımı alanı eğitimdir. Eğitim amaçlı bloglar öğrenciler ya da öğretmenler ya da öğrenciler ve öğretmenlerin işbirliğinde kurulabilmektedir. Bu tip bloglarda genellikle öğretmenler ders akışını, derslerle ilgili bilgileri, ders notlarını ve ders üstüne görüşlerini paylaşırken; öğrenciler derste ne öğrendikleri hakkında fikir belirtebilmekte, ortak çalışmalar yürütebilmekte ve ders notlarını ve yardımcı kaynakları paylaşabilmektedir. Curran ve Marshall (2011)'a göre eğitsel bloglar öğrencileri daha çok okumaya ve araştırma yapmaya teşvik etmekte aynı zamanda birçok kişi öğrencilerin yazdıklarını görebildiği için yazma yeteneklerini geliştirebilmektedir. Huette (2006)'nin aktardığına göre de eğitim amaçlı bloglar eleştirel ve analitik düşünmeyi geliştirmeye yardımcı olmakta; yaratıcı, sezgisel ve çağrışımsal düşünceye kapı açmakta; bilgiye erişimi kolaylaştırmakta ve dayanışma ve sosyal etkileşim ortamı oluşturmaktadır.

H. Nam Kim (2008)'in araştırmasında bilgisayar aracıllı̆̆ıyla eğitim verilen diğer ortamlar ve bloglar karşılaştırılmış ve blogların bilgisayar aracılığıyla eğitim ortamlarının eksikliklerini giderebilecek araçlar olabileceği ortaya koyulmuştur. Bilgisayar aracılığıyla eğitim ortamlarında öğrencilerin sisteme giriş yapması, kayıt olması, tartışmaları takip etmesi ve sistemi kullanmayı öğrenmesi gerekmektedir. Bu süreç zaman aldığı ve belirli yeterlikleri gerektirdiği için öğrencilerin motivasyonlarını azaltabilmektedir. Blogların ise hem kullanımı kolaydır hem de bloglara erişim çok hızlı olmakta ve blog sistemini kullanmak görece daha az zaman ve bilgi gerektirmektedir. J. Farmer (2006)'in iddiasına göre de bloglar ögrencilerin kendi ihtiyaçlarına göre tasarladıkları ortamlar olabilir ve böylece daha katılımcı bir eğitim sağlanabilir. Aynı zamanda bloglar öğrenciler arasında kendilerini özgürce ifade ettikleri bir grup hissi yaratma potansiyeline sahiptir. Öğrenciler derse ait sorumlukları yerine getirdiklerinde bloglarına yüklemekte ve dersi alan diğer öğrencilere de açmaktadırlar. Öğrenciler arasındaki sosyal etkileşim, J. Hsu (2007)'ye göre daha çok bilgi merkezli olmakta, öğrenciler hem dersi alan diğer öğrencilerden hem dersi vermekle yükümlü olan öğretmenden hem de alandaki diğer uzmanlardan dönüt alabilmektedirler.

Eğitim alanında bloglar bilgisayar aracılığıyla eğitime katkılar sağlamakta, öğrenciler arasında bir sosyal etkileşim alan hâline gelmekte ve yazdıkları aracılığıyla bireysel olarak kendilerini ifade etmelerine olanak tanımaktadır. Yeni nesil neredeyse ağın içine doğmakta ve geleceğin dijital yerlileri olarak yetişmektedir, bu nedenle geleceğin öğrencilerinin bilgiyi edinme biçimlerinin de değişik olacağı öngörülebilir. Diğer çevrimiçi uygulamalarla bir araya getirildiğinde eğitsel bloglar kıymetli eğitim uygulamaları olabilir. Bunların yanında $\mathrm{H}$. Nam Kim (2008)'in araştırmasında ortaya koyulduğu gibi eğitim amaçlı bloglar bazen beklenen sonuçları doğurmamakta öğrenci etkileşimi ve motivasyonu düşük kalabilmektedir. Bu nedenle blogların eğitim amacıyla kullanımında kültürel, bireysel farklılıklara dikkat edilmeli ve internete ulaşımda ülkeler ve bölgeler arası eşitsizlikler dikkate alınmalıdır.

\section{Pazarlama}

Blogların önemli kullanım alanlarında biri de pazarlama ve halkla ilişkiler alanıdır. İş dünyası ile ilgili dergilerde 2000'lerin ortalarında pazarlama ve halkla ilişkilerde blogların önemine dair haberlerin kapladığı alan artmıştır. 2005 Ocak ayında dünyaca ünlü Fortune dergisi blogların reklamcılık, pazarlama ve halkla ilişkiler alanlarındaki çalışma pratiklerini değiştirdiğini iddia etmiş; The Harvard Buniness blogları iletişime en yatkın mecra olarak işaret etmiştir (Kirkpatrick ve Roth, 2005; Sawhney, 2005). J. Hill (2005)'e göre 1990'larda ortaya çıkan ya da yaygınlık kazanan ağızdan ağıza pazarlama, gerilla pazarlama, görsel pazarlama gibi birçok yeni pazarlama yöntemi için bloglar uygun bir ortam sunmakta ve bu 
yöntemlerin ortaya çıktığı ya da yaygınlık kazandığı kültürel ve sosyal konjonktüre uygunluk göstermektir.

Blogların pazarlamada etkin olarak kullanılması pazarlamanın kendi değişen doğası ile paraleldir. İkinci Dünya Savaşı'ndan sonraki dönemde kitlesel üretimin yanında özelleştirilmiş ürünler üretebilin teknolojiler gelişmiş, kitle iletişim araçları yaygınlaşmış (Edwards, 2000); bireyin istek ve arzuları ürünlerin işlevsel özelliklerinin önüne geçmiştir (Baudrillard, 2009). Müşteriler artık işletmeler için tanımsız yı ğınlar değil, özelleşmiş bireyler hâline gelmişler ve her bir müşterinin istek ve arzularına daha çok önem verilmeye başlanmıştır. Ürünlerin sağlam ve dayanıklı olması ilkesi yerini kişinin fantezilerine hitap eden ürünlere bırakmıştır. Bloglar, işletmelerin müşterileri ile "kişiselleştirilmiş bir ilişki" kurmasına izin vermektedir (Kaye, 2003: 18). Bloglar aracığıyla işletmeler kendi içindeki gelişmeleri haber bültenleri şeklinde yayınlayabilmekte, yeni ürünleri ve projeleri hakkında müşterilerini bilgilendirebilmekte; en önemlisi de müşterilerinden etkili bir biçimde geri dönüş alabilmektedir.

Blogların pazarlama alanın bir diğer kullanımına Hill (2005) işaret etmektedir. Bloglar sayesinde alt kültürlere ait müşterilerin ya da niş pazarların takibi kolaylaşmakta, küçük işletmeler doğrudan müşterileri ile iletişim hâlinde olmakta ve işletmeler ve müşteriler arasında duygusal ilişkiler vuku bulmaktadır.

Şirketler blogları topluluklar oluşturmak için de kullanabilmektedirler. Shingha ve arkadaşları (2008), şirketlerin blogları pazarlama alanında bu tip kullanımını altı strateji çerçevesinde ele almaktadır. Bu stratejilerden birincisi yukarıda da değinilen müşteriler ile bağlantılı olmadır. İkinci strateji ise müşteriler hakkında kişiselleştirilmiş bilgi toplanması ve ürün geliştirimi ya da tanıtımı faaliyetlerinde bu bilgi havuzlarına başvurulmasıdır. Diğer bir pazarlama stratejisi ise nesiller arası köprüler kurmaktadır. Görece genç ve görece yaşlı nesillerin internet kullanım alışkanlıkları farklılıklar göstermekte, kullandıkları dil ve üslupları farklılaşmaktadır. Firmalar bloglarını farklı nesillere farklı şekillerde hitap ederek kullanabildikleri gibi gelecek nesillerin eğilimlerini de blogları aracılığıyla topladıkları verilerden saptamaya çalışmaktadırlar. Pazarlama amaçlı bloglar, geleneksel medya reklamlarında olduğu gibi ünlülere ve kanaat önderlerine ev sahipliği yapabilmektedirler; ancak bu stratejinin güçlü yanı ünlülerin ve kanaat önderlerinin geleneksel medyaya göre daha samimi bir ortamda bulunması ve ulaşılabilir olmasıdır. Küçük şirketler de blogları içinde bulundukları alana dair teknolojik, sosyal, kültürel bilgi ve haberler yayınlayarak kendi uzmanlık alanlarını kanıtlama aracı olarak da kullanabilmektedirler (Stone, 2004). Singh ve arkadaşlarının (2008) işaret ettiği diğer bir özellik blogların küresel olması, ağda küresel bir ulaşıma olanak tanıması dolasıyla şirketlerin bloglar aracılığıyla küresel bir platforma taşınmasıdır. Son olarak tekrar değinilmesi gerek özellik ise bloglar şirket ve müşteri arasında samimi bir ortam yaratmakta, şirketlere müşterilerini tanıma firsatı sunmalarıdır.

Pazarlama alanında bloglar şirketlere müşterileri ile kişiselleştirilmiş iletişim kurma imkanı sunarken, marka ya da firma etrafında toplanan bir topluluk hissi yaratmakta, müşterilerine dair bilgileri arşivleyerek araştırma geliştirme, ürün ve tanıtım tasarımı aşamalarında hazır bir bilgi sunmaktadırlar. Bu hâlleriyle bloglar bugünün olduğu gibi geleceğin de önemli bir pazarlama aracı olacak gibi görünmektedirler.

\section{SONUÇ}

Bloglar ya da internet günlükleri kişilerin çevrimiçi günlükleri olarak ortaya çıkmış, kişisel kullanım alanların başlayarak birçok alana yayılmıştır. Kişisel kullanıcılar blogları ilgi 
alanları hakkında paylaşımlarda bulunmak, bir toplulukta yer almak, fikir ve duygularını paylaşmak gibi amaçlarla kullanırken; blogların gazetecilik, politika, eğitim, pazarlama ve bu çalışmada ele alınamayan birçok alanda farklı kullanım amaçları ve stratejileri mevcuttur. Özellikle gazetecilik ve politika alanlarının birleşiminden meydana gelen e-devlet ve eyurttaşlık uygulamaları bloglar ekseninde tartışılan güncel konulardır. Blogları da kapsayan sosyal medya sayesinde yeni bir kamusal alanın ortaya çıktığı ve bu kamusal alanın geleneksel medyaya göre daha zor manipüle edilebilir; daha katılımcı ve özgür olduğu iddia edilmektedir.

Gazetecilik alanında yerinden ve hızlı haber üretmeye el vermeleri ile bloglar yurttaş gazeteciliğini destekler ve güçlendirir niteliktedir; ancak haber blogların bir konsensüs çerçevesinde regülasyonu sağlanmadığı sürece haber kaynağının belirsizliği ve yanlı yaklaşımların çokluğu nedenleri ile çok kolay manipüle edilebileceği unutulmamalıdır. Politika alanında da benzer durumlar söz konusudur. Haberlerin hızlı dolaşımı nedeni ile doğruluğu genellikle araştırılmamakta ve bloglar kulaktan dolma bilgiler üretebilmektedir. Politika alanında kitlelerin kulaktan dolma bilgilerle hareket etmesi hayati sonuçlara yol açabilir. Eğitim alanında dijital yerliler için yeni bir eğitim ortamı sunsalar da bloglar siber zorbalık gibi internet suçlarına açık bir ortam olarak karşımıza çıkmaktadır. Bunun yanında özellikle eğitim alanında toplumsal ve kültürel farklar göz ardı edilmemeli ve ülkelerin ve bölgelerin internete eşitsiz ulaşımı dikkate alınmalıdır. Belki de bloglar kapitalist sistem içinde en çok şirketlerin pazarlama uygulamalarında daha az riskle çalışmaktadır; ancak bu alanda da çeşitli karalama kampanyalarının ve asılsız haberlerin şirketlerin imajına kalıcı ve ağır hasarlar verebildiği akılda tutulmalıdır.

Sonuç olarak bloglar birçok kolaylık ve avantaj sunmalarının yanında aşılması gereken engeller ve zorluklar da barındırmaktadır; gelecekte hem blogların sunduğu avantajları hem de zorlukları göz önüne alarak bloglarla ilgili çalışmalar yürütmek daha verimli olacak gibi görünmektedir.

\section{KAYNAKLAR}

Adamic, L. ve Glance, N. (2005). The Political Blogosphere and the 2004 U.S. Election: Divided They Blog. LinkKDD '05. New York: Proceedings of the 3rd International Workshop on Link Discovery. 36-43.

Akar, E. (2006). Blogla Pazarlama. İstanbul: Tiem.

Akar, E. (2009). Pazarlama Bağlamında Geleneksel ve İnternette Ağzından Ağıza İletişim: Kuramsal Bir Çerçeve. Erciyes Üniversitesi İktisadi ve İdari Bilimler Fakültesi Dergisi, 32, 113-134.

Andrews, P. (2003). Is Blogging Journalism?. Neiman Reports. Sonbahar 2003. http://www.nieman.harvard.edu/reportsitem.aspx?id=101027 adresinden 19.11.2013 tarihinde erişildi.

Bahnisch, M. (2006). The Political Uses of Blogs. Uses of Blogs (Ed: A. Bruns ve J. Jacobs) içinde. New York: Peter Lang. 139-149.

Barlow, A. (2008). Blogging America, The New Public Sphere. Londra, Praeger. Baudrillard, J. (2009). Gösterge Ekonomi Politiği Hakkında bir Eleştiri (Çev: O. Adanır). İstanbul: Boğaziçi Üniversitesi.

Bourdieu, P. (1984). Distinction (Çev: R. Nice). Londra: Routledge. 
Brown, L. A. (2005). Technology-based Models. Encyclopedia of Virtual Communities and Tecnologies (Ed: S. Dasgupta) içinde. Londra: Idea Group. 434-438.

Bruns, A. ve Jacobs, J. (2006). Introduction. Uses of Blogs (Ed: A. Bruns ve J. Jacobs) içinde. New York: Peter Lang. 1-8.

Chomsky, N. (1993). Medya Denetimi - Immediast Bildirgesi (Çev: Ş. Süre). İstanbul: Tüm Zamanlar.

Cortini, 2009. New Horizons in CSP and Employee/Employer Relationship: Challenges and Risks of Corporate Weblogs”. Employee Responsibilities and Rights Journal, 24, 4, 291 303.

Curran, K. Ve Marshall, D. (2011). Blogs in Education. Elixir Adv. Engg. Info, 36, 35153518.

Çelebi, G. (2006). Müşteri ve Paydaşlarla Samimi İletişimin Kapısı Kurumsal Bloglar.

Ekonomik Forum Dergisi, 78-79.

Dahan, G. S. (2012). Sanal Dünyada E-Ağzından Ağıza Pazarlama Üzerine Bir İnceleme. Sosyal Medya, Akademi içinde (Ed: T. Kara ve E. Özgen). İstanbul: Beta. 83-112.

Dilmen, N. E. (2007). Yeni Medya Kavramı Çerçevesinde İnternet Günlükleri-Bloglar ve Gazeteciliğe Yansımaları. Marmara İletişim Dergisi 12, 114-131.

DiNucci, D. (1999). Fragmented Future. Print, 53(4), 32.

Edwards, T. (2000). Conradictions of Consumption. Philadelphia: Open University.

Farmer, J. (2006). Blogging to Basics: How Blogs are Bringing Online Education Back from the Brink. Uses of Blogs (Ed: A. Bruns ve J. Jacobs) içinde. New York: Peter Lang. 91103.

Farrell, H., Lawrence, E. ve Sides, J. (2008). Self-Segregation or Deliberation? Blog Readership, Participation, and Polarization in Amrican Politics. The Mifwest Political Science Association Conference, Chicago, 3-6 Nisan.

Freidman, 2010. Blogging vs. Journalism: The Ongoing Debate. TNW News. http://thenextweb.com/us/2010/08/18/blogging-vs-journalism-the-ongoing-debate/ adresinden 19.11.2013 tarihinde erişildi.

Genç, H. (2010). İnternetteki Etkileşim Merkezi Sosyal Ağlar ve E-İş 2.0 Uygulamaları. Akademik Bilişim '10 - XII. Akademik Bilişim Konferansı Bildirileri, 481-487.

Habermas, J. (2012). Kamusal Alanın Yapısal Dönüşümü (Çev: M. Sancar ve T. Bora). İstanbul: İletişim.

Hill, J. (2005). The Voice of the Blog: The Attitudes and Experiences of Small Business Bloggers Using Blogs as a Marketing and Communication Tool. Yayımlanmamış Yüksek Lisans Tezi. Liverpool: The University of Liverpool.

Howard, P. N., Duffy, A., Freelon D., Hussain, M., Mari, W. ve Mazaid, M. (2011), "Openning Closed Regimes: What Was the Role of Social Media During the Arap Spring?”, http://pitpi.org/index.php/2011/09/11/opening-closed-regimes-what-was-therole-of-social-media-during-the-arab-spring/ adresinden 05.06.2013 tarihinde erişildi.

Hsu, J. (2007). Innovative Technologies for Education and Learning: Education and Knowledge-oriented Applications of Blogs, Wikis, Podcasts, and More. International Journal of Information and Communication Technology Education, 3, 3, 70-89.

Huang, C., Shen, Y., Lin, H. ve Chang, S. (2007). Bloggers' Motivations and Behaviors: A Model. Journal of Adverstising Research, Aralık, 472-484.

Huette, S. (2006). Blogs in Education. http://elearningup.org.in/UploadArticlePDFFiles/BlogsInEducation60563ee4-f40f-46c1-9e8cccf9f43b2ebe.pdf adresinden 22.11.2013 tarihinde erişildi.

Hudson, D. L. (2008). Blogging. New York: Chelsea House. 
Johnson, T. J. ve Kaye, B. K. (2004). Wag the Blog: How Reliance on Traditional Media and the Internet Influence Credibility Perceptions of Weblogs among Blog Users. Journalism and Mass Media Communication Quarterly, 81, 3, 622-642.

Johnson, Z. (2012). State of Blogging World 2012. http://www.blogworld.com adresinden 14.11.2013 tarihinde erişildi.

Kaplan, A. M. ve Haenlein, M. (2010). Users of the World, Unite! The Challenges and Oppurtunities of Social Media. Business Horizons, 53, 59-68.

Kaye, K. (2003). Business Blogs. Andover: Up2Speed.

Kawamura, Y. (2005). Fashion-ology. New York: Berg.

Kinsela, S., Budura, A., Skobeltsyn, G. Michel, S., Breslin, J. G. ve Aberer, K. (2010). From Web 1.0 to Web 2.0 and Back - How did your Grandma Use to Tag?. ACE '10 Advances in Computer Entertainment Technology Conference, Taipei, Tayvan.

Kim, H. N. (2008). The Phenomenon of Blogs and Theoretical Model of Blog Use in Educational Contexts. Computers \& Education, 51, 1342-1352.

Kirkpatrick, D. ve Roth, D. (2005). Why There's No Escaping the Blog. 151, 1, 64.

Köse, H. (2007). Alternatif Medya. İstanbul: Yirmi Dört.

Köseoğlu, Ö. (2012). Sosyal A ̆g Sitesi Kullanıcılarının Motivasyonları: Facebook Üzerine bir Araştırma. Selçuk İletişim, 7, 2, 58-81.

Krishnamurthy, B. ve Cormode, G. (2008). Key Differences between Web 1.0 and Web 2.0. First Monday, 13(6), http://firstmonday.org adresinden 14.11.2013 tarihinde erişildi.

Loewenstein, A. (2008). The Blogging Revoluation. Melbourne: Melbourne University.

Marken, G. A. (2006). Bloggig... Look, Think Before You Leap or Push the Boss. Public Relations Quarterly, 52, 2, 37-39.

Marvick, A. (2011). Conspicous and Authentic: Fashion Blogs, Style, and Consumption. International Communication Association, http://www.tiara.org/papers/marwick_conspicuousauthentic.pdf adresinden 08.01.2013 tarihinde erişildi.

McLean, J. (2009). The State of the Blogshpere 2009. http://technorati.com adresinden 07.01.2013 tarihinde erişildi.

Murugesan, S. (2007). Understanding Web 2.0. IT Pro, Temmuz-A ğustos 2007, 34-41.

Nardi, B. A, Schiano, D. J., Gumbrecht, M. ve Swartz, L. (2004). Why We Blog. Communication of the ACM, 47,12, 41-46.

O'Reilly, T. (2005). What is Web 2.0: Design Patterns and Business Model for the Next Generation of Software, http://www.oreillynet.com adresinden 14.11.2013 tarihinde erişildi.

Özgüner Kılıç, H. (2011). Kurumsal Blog Sahibi Olmanın Şirketlerin Gelir ve Kârına Etkisi: Fortune 500 Üzerine bir Araştırma. Eskişehir Osmangazi Üniversitesi İİBF Dergisi, 6, 1, 139-162.

Pagett, K. (2010). Will 2020 Still be a Greater Year to be a Fashion Blogger. Digital Research and Publishing, 7PM, 123-130.

Perlmutter, D. D: (2008). Blogwars. New York: Oxford University.

Prensky,. M. (2001). Digital Natives, Digital Immigrants. On the Horizon, 9,5, 1-6.

Saktanber, B. (2007). İmdat değil Yaşasın! Radikal 2. http://www.radikal.com.tr/ek_haber.php? ek=r2\&haberno=6622 adresinden 19.11.2013 tarihinde erişildi.

Sawhney, M. (2005). Blog-trolling in the Bitstream. The Harward Business Review. 83, 2, 39. Shingha, T., Veron-Jacksonb, L. ve Cullinane, J. (2008). Blogging: A New Play in Your Marketing Game Plan. Business Horizons, 51, 281-292. 
Singer, J. B. (2006). Journalists and New Bloggers: Complements, Contradictions, and Challenges. Uses of Blogs içinde (Ed: A. Bruns ve J. Jacobs). New York: Peter Lang. 2331.

Silverman, G. (2006). Ağızdan Ağıza Pazarlama, Dünyanın En Güçlü Pazarlama Yöntemi Womm'un 28 Sirrı. İstanbul: MediaCat.

Stone, B. (2004). Who Let the Blogs Out?. New York: St. Martin's.

Sysomos. (2012). Inside Blog Demographics. http://www.sysomos.com/reports/bloggers adresinden 14.10.2013 tarihinde erişildi.

Wright, J. (2005). Blog Marketing. New York: McGraw-Hill. 